\title{
The Effect of Bromhexine and Thyme Oil on Enhancement of the Efficacy of Tilmicosin against Pasteurellosis in Broiler Chickens
}

\author{
Abeer M Radi ${ }^{1}$, Nema S Shaban ${ }^{1}$, Fatma I Abo El- Ela ${ }^{1}$, Elham Ahmed Mobarez ${ }^{2}$,El-Gendy AAM ${ }^{1}$ and El-Banna HA ${ }^{3 *}$ \\ ${ }^{1}$ Department of Pharmacology, Faculty of Veterinary Medicine, Beni-Suef University, 62511, Egypt. \\ ${ }^{2}$ Department of Pharmacology, Animal Health Research Institute, Dokki, Giza, Egypt. \\ ${ }^{3}$ Department of Pharmacology, Faculty of Veterinary Medicine, Cairo University, 12211, Giza, Egypt. \\ "Corresponding author's Email: drelbanna3@yahoo.com; ORCID: 0000-0003-4476-7775
}

Received: 01 Feb. 2020

Accepted: 09 Mar. 2020

\begin{abstract}
Pasteurella multocida is one of the commensal flora of the upper respiratory tract. Under stress conditions, it may be involved as a secondary agent in various respiratory syndromes and caused high mortality as well as significant economic losses in chickens. This study evaluated the effect of bromhexine or thyme oil on enhancement of efficacy of tilmicosin in treatment of avian pasteurellosis. A total of 63 adult chickens were infected by Pasteurella multocida and classified into seven groups and treated as follow; non-infected non-treated group (control negative), infected non-treated group (control positive), group infected and treated by tilmicosin alone, group infected and treated by bromhexine alone, group infected and treated by thyme oil alone, group infected and treated by tilmicosin+bromhexine, and group infected and treated by tilmicosin+thyme oil. Clinical signs, mortality rate, bacterial re-isolation, hematobiochemical and histopathological parameters were determined. The results showed a significant decrease in mortality, bacterial re-isolation as well as clinical signs in combined treated groups compared to tilmicosin group as well as improvement in hematobiochemical and histopathological parameters of combined treated groups. Furthermore, the combination of tilmicosin and bromhexine or thyme oil was more potent in the treatment of pasteurellosis in chickens than each treatment alone. Finally, the clinically observed damage in chickens infected with $P$. multocida can be ameliorated by a combination of tilmicosin with bromhexine or thyme oil. This protective effect could improve the use of antibiotics in poultry farms as well as reduce human exposure to antibiotic residues and bacterial resistance to antibiotics.
\end{abstract}

Keywords: Bromhexine, Chickens, Efficacy, Pasteurella Multocida, Thyme oil, Tilmicosin

\section{INTRODUCTION}

Fowl cholera is a contagious bacterial disease caused by Pasteurella multocida affecting domesticated and wild birds that occur sporadically or enzootically in most countries of the world with significant economic losses due to its high mortality (Glisson et al., 2013).

Tilmicosin is a 16-membered ring macrolide, which penetrates the microbial cell membrane and suppresses the synthesis of protein by the 50s ribosomal subunit which leads to the synthesis of incomplete peptide chains (Seiple et al., 2016). Tilmicosin is characterized by low plasma concentrations but high and persistent tissue concentrations, indicating high efficacy of the drug (Mestorino and Errecalde, 2004). It is an effective remedy for a wide range of Gram-positive organisms, some Gramnegative bacteria, as well as atypical bacteria (ElMahmoudy et al., 2018).
Bromhexine hydrochloride is a quinazoline alkaloid obtained from Adhatoda vasica plant which increases the bronchial secretions and reduces their viscosity. Also, it elevates the immunoglobulin levels in airway secretions, thins and loosens mucus to help the treatment of chest congestion thus it is often added to cough syrups (Gubbi et al., 2009). It is used as a mucolytic expectorant, which increases the production of serous mucus in the respiratory tract and makes the phlegm thinner thereby easing cough (Siddappa and Hanamshetty, 2016).

Medicinal herbs play an essential role in the fields of drug development due to their safety, easy accessibility, as well as restricted side effects (Pathak and Das, 2013). The essential oils are volatile complex compounds formed by aromatic plants as secondary metabolites characterized by a strong odor (Bakkali et al., 2008). Thymol and carvacrol were the major derived essential oils of Thymus vulgaris which have shown antioxidant, antibacterial, antifungal, 
anticoccidial properties and positive effect on growth performance properties in broilers (Aljabeili et al., 2018). It has been shown that Thymus vulgaris essential oil had the best antibacterial activity (Santurio et al., 2014). However, little information is available on the antibacterial activity of Thymus vulgaris essential oil against $P$. multocida, and no study has been conducted to investigate its synergistic effect with tilmicosin against $P$. multocida.

This work was designed to compare the efficacy of tilmicosin alone and in combination with bromhexine or thyme oil in the treatment of experimentally infected broiler chickens with $P$. multocida.

\section{MATERIALS AND METHODS}

\section{Drugs}

A-Tilmicosin phosphate: It was kindly provided by Pharma- swede ${ }^{\circledR}$ company, Egypt as a white powder (80 $\%$ ), well soluble in water. Chemical name: 20 -Deoxo-20(3, 5-dimethyl-1-piperidinyl) desmycosin.

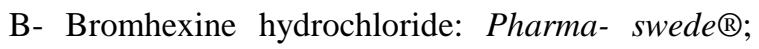
Egyptian company; kindly provided it in the form of white powder $(98 \%)$, poorly soluble in water but soluble in $\mathrm{N}$ methyl pyridine/ propylene glycol (NMP/PG) (50\%: 50\%) solvent. Chemical name: 2-amino-3, 5- dibromobenzyl (cyclohexyl) methylamine hydrochloride.

C-Thyme oil: It was kindly provided by Pharmaswede ${ }^{\circledR}$ company Egypt as oily solution (100\%), poor soluble in water. Chemical name: 3, 7-dimethylocta-1, 6dien-3-ol; 2-(4-methylcyclohex-3-en-1-yl) propan-2-ol; 1 methyl-4-propan-2-ylbenzene; 4-methyl-1-propan-2ylbicyclo [3.1.0] hexan-4-ol; 5-methyl-2-propan-2ylphenol.

Chickens: This study was carried out on 63, 35-dayold broilers chicken (2.5-3 kg) of both sexes. Balanced ration and water ad-libitum were provided for birds. Birds were kept under proper hygienic conditions and left without treatment for 15 days before the onset of the experiment for acclimatization and ensuring complete clearance of any drugs.

Bacterial strain: $P$. multocida serotype $\left(\mathrm{A}_{5}\right)$ was obtained from the Microbiology Department, Animal Health Research, Institute, Dokki, Egypt. Preparation of the virulent strain was performed by intramuscular inoculation of mature chicken with $0.5 \mathrm{ml}$ of 18 hour broth culture of $P$. multocida containing $3 \times 10^{8}$ Colony Forming Unit (CFU) viable organism (Amany and Abd-Alla, 1997). After the appearance of clinical signs and before death, the heart was taken, splitted on Brain Heart Infusion Agar
(BHIA) and incubated at $37^{\circ} \mathrm{c}$ for 24 hours. After subculturing of bacteria into Brain heart infusion agar at $37^{\circ} \mathrm{C}$ for 24 hours, the uniform-sized colonies were selected and diluted with sterile physiological saline. The viable count was adjusted by Macfarland tube No. 1 to obtain $3 \times 10^{8}$ $\mathrm{CFU} / \mathrm{ml}$. The infective dose for each chicken was $0.5 \mathrm{ml} /$ bird intramuscular into the breast muscle.

\section{Ethical approval}

The experiment was conducted in accordance with the principles and guidelines of the Institutional Animal Care and Use Committee (IACUC) of the faculty of veterinary medicine, Cairo University.

\section{Experimental design}

The efficacy of tilmicosin alone or in combination with bromhexine hydrochloride or thyme oil against experimental infection with $P$. multocida was studied according to the method described by Amany and AbdAlla (1997). The mature broilers (63 birds) were randomly divided into 7 groups ( 9 birds of each). The feed and water were supplied to the birds ad libitum throughout the experiment. The birds were kept under investigation for two weeks to ensure the removal of any antibacterial agent traces before the onset experiment. The group 1 left as control non-infected non-treated, whereas other experimental groups were intramuscularly injected into the breast muscle with $0.5 \mathrm{ml} /$ birds of $18-24$ hours broth culture of $P$. multocida containing $3 \times 10^{8} \mathrm{CFU} / \mathrm{ml}$.

\section{Treatment regimens}

Group (1): non-infected non-medicated (control negative).

Group (2): infected non-treated (control positive).

Group (3): infected and treated with tilmicosin phosphate at a dose level of $20 \mathrm{mg} / \mathrm{kg}$ (Amer et al., 2009) for 12 hours.

Group (4): infected and treated with bromhexine hydrochloride ( $1 \mathrm{mg} / \mathrm{kg}$ b.wt) for 12 hours.

Group (5): infected and treated with thyme oil $20 \%$ $(0.2 \mathrm{ml} / \mathrm{l})$ (Feizi et al., 2013) for 12 hours.

Group (6): infected and treated with tilmicosin phosphate $(20 \mathrm{mg} / \mathrm{kgb} . \mathrm{wt})$ in combination with bromhexine hydrochloride ( $1 \mathrm{mg} / \mathrm{kg}$ b.wt) for 12 hours.

Group (7): infected and treated with tilmicosin phosphate $(20 \mathrm{mg} / \mathrm{kg} . \mathrm{b} . \mathrm{wt})$ in combination with thyme oil extract $20 \%(0.2 \mathrm{ml} / \mathrm{l})$ for 12 hours.

All medications were given orally in drinking water one-hour post-infection and for 3 successive days. The birds were examined for 14 days post-infection for the 
clinical signs, mortality rate, morbidity, and histopathological examination. Blood samples were taken at $3^{\text {rd }}$ day and $14^{\text {th }}$ days post-infection and divided into 2 parts; one part on EDTA for determination of erythrocytes (RBCs) count (Feldman et al., 2000), Hb concentration (Varley, 1980), total and differential leucocytic count (Jain, 1986) whereas the second part was collected into plain centrifuge tube for serum separation and determination of Aspartate Aminotransferase (AST) and Alanine Aminotransferase (ALT) activities (Reitaman and Frankel, 1957), Creatinine (Doolan et al., 1962) and uric acid (Kageyama, 1971). The samples were taken from the post-mortem examined (liver, lungs, and heart) at $3^{\text {rd }}$ day of infection, one and $14^{\text {th }}$ day post-infection were incubated on nutrient broth at $37^{\circ} \mathrm{C}$ for 24 hours, then subcultured on nutrient agar and BHIA plates for 24hours at $37^{\circ} \mathrm{C}$, suspected colonies were identified and positive or negative culture results were recorded.

\section{Statistical analysis}

The results are presented in the form of mean \pm standard error of the mean (S.E.M.). Statistical significance was determined by one-way analysis of variance (ANOVA) according to (Sndecor and Cochran, 1982), followed by Tukey's posthoc test for multiple comparisons using SPSS (version 20.0) software (IBM SPSS Statistic 20.0, Armonk, NY, USA). The $P$ - values less than 0.05 were considered statistically significant.

\section{RESULTS}

\section{Clinical signs and mortality rate}

Inoculation with $P$. multocida induced severe symptoms in non-medicated chickens characterized by congestion of mucous membranes, depression, ruffled feathers, off food, greenish diarrhea, cough, and nasal discharge, gasping, swelling of the wattles, lameness, sinusitis, and ophthalmia or even sudden death. These signs appeared on the first day after inoculation. Treatment with tilmicosin in combination with bromhexine or thyme oil significantly reduced the prevalence and severity of clinical signs than each drug alone. A mortality rate was recorded during the experiment in each group and calculated as a percent $(\%)$ as showed in table 1.

Bacterial re-isolation: Pasteurella multocida was reisolated from all organs of infected non-medicated birds $(100 \%)$, whereas non-infected non-medicated chickens showed no bacterial re-isolation. Similarly, medication with bromhexine didn't reduce bacterial re-isolation $100 \%$. Drug with thyme oil $20 \%$ reduced bacterial re- isolation to $88.8-100 \%$. The combination of tilmicosin with bromhexine reduced the incidence of re-isolation to $11.1-33.3 \%$ compared to $44.4-55.5 \%$ when used tilmicosin alone as well as the combination of tilmicosin with thyme oil reduced bacterial re-isolation to $11.1-22.2 \%$ compared to $44.4-55.5 \%$ when used tilmicosin solely as observed in table 2 .

\section{Hematobiochemical parameters}

The results of blood picture revealed anemia indicated by significant reduction in RBCs count and $\mathrm{Hb}$ concentration; also leukocytosis indicated by considerable increase in neutrophils in non-treated, bromhexine and thyme oil-treated groups at $3^{\text {rd }}$ day and $14^{\text {th }}$ day of medication and in tilmicosin treated group at $3^{\text {rd }}$ day of treatment, compared to control negative group, tilmicosin/bromhexine combination and tilmicosin/thyme oil combination at $3^{\text {rd }}$ day and $14^{\text {th }}$ of medication. The effect of treatment with tilmicosin alone or in combination with either bromhexine or thyme oil on liver and kidney functions of chickens inoculated with $P$. multocida on $3^{\text {rd }}$ day and $14^{\text {th }}$ day of the experiment showed significant elevation in the values of ALT, AST, uric acid and creatinine in non-treated, bromhexine and thyme oiltreated groups and tilmicosin treated group at $3^{\text {rd }}$ day of the experiment compared to control negative group, tilmicosin/bromhexine, and tilmicosin/thyme oil-treated groups at $3^{\text {rd }}$ day and $14^{\text {th }}$ of medication as recorded in tables 3,4 and 5 .

\section{Histopathological findings: \\ - Macroscopical findings}

Macroscopically, the liver characterized by enlargement, severe congestion with friable texture and pointed edges, pinpoint necrotic foci, fibrinous perihepatitis. These pathological lesions were markedly decreased in tilmicosin treated groups at $14^{\text {th }}$ of the experiment, whereas they significantly decreased in tilmicosin/bromhexine and tilmicosin/thyme oil-treated groups at $3^{\text {rd }}$ and $14^{\text {th }}$ days of the experiment.

\section{- Microscopical lesions}

Microscopically examination of the lungs of infected non-treated $\left(\mathrm{G}_{2}\right)$, Tilmicosin $\left(\mathrm{G}_{3}\right)$, Bromhexine $\left(\mathrm{G}_{4}\right)$ and Thyme oil $\left(\mathrm{G}_{5}\right)$ treated groups during $3^{\text {rd }}$ day and $14^{\text {th }}$ post medication showed severe congestion, perivascular edema and lymphocytic infiltrations in comparison to nearly normal lung in control negative group $\left(\mathrm{G}_{1}\right)$ and combined treated groups $\left(\mathrm{G}_{6,7}\right)$ as illustrated in Figures 1 and 2. The liver of $\left(G_{2}, 3,4,5,7\right)$ showed severe vacuolar degeneration in comparison to mild vacuolar degeneration 
in $\left(\mathrm{G}_{6}\right)$ on $3^{\text {rd }}$ day. At $14^{\text {th }}$ post medication, very mild congestion, slight leucocytic infiltrations are shown in $\left(\mathrm{G}_{3}\right.$, $\left.6,{ }_{7}\right)$. But $\left(G_{1}, 2,4\right.$ and $\left._{5}\right)$ gave the same results which observed on the $3^{\text {rd }}$ day of the experiment, as shown in Figures 3 and 4 . The heart of groups $\left(G_{2}, 3,4,5\right)$ showed severe congestion of coronaries with severe perivascular edema in comparing with focal lymphocytic infiltrations in the myocardium in $\mathrm{G}_{6}$ and slight congestion of coronaries with focal necrosis in some muscle bundles in $\mathrm{G}_{7}$ on $3^{\text {rd }}$ day of experiment whereas at $14^{\text {th }}$ of the experiment; the same results were obtained in groups (2, 4 and 5) compared to normal cardiac muscle in groups (1, 6 and 7) as shown in Figures 5 and 6.

Table 1. Effect of different medications on mortality rate of experimentally infected broiler chickens with Pasteurella multocida.

\begin{tabular}{lcc}
\hline Treatment groups & Dead birds/total birds & Mortality $(\%)$ \\
\hline Non-infected non-treated group (Control negative) & $0 / 9$ & $0 \%$ \\
Infected non-treated group (Control positive) & $4 / 9$ & $44.4 \%$ \\
Tilmicosin group & $1 / 9$ & $11.1 \%$ \\
Bromhexine group & $3 / 9$ & $33.3 \%$ \\
Thyme oil group & $2 / 9$ & $22.2 \%$ \\
Tilmicosin + Bromhexine group & $0 / 9$ & $0 \%$ \\
Tilmicosin + Thyme oil group & $0 / 9$ & $0 \%$ \\
\hline
\end{tabular}

Table 2. Effect of different medications on bacterial re-isolation from different organs of experimentally infected broiler chickens with Pasteurella multocida

\begin{tabular}{|c|c|c|c|c|c|c|}
\hline \multirow{3}{*}{ Treatment groups } & \multirow{3}{*}{ Organ } & \multirow{2}{*}{\multicolumn{3}{|c|}{$\begin{array}{c}\text { Number of positive cases } \\
\text { day post-infection }\end{array}$}} & \multirow{3}{*}{$\begin{array}{c}\text { Total No. of positive cases / } \\
\text { total No. of examined } \\
\text { chickens }\end{array}$} & \multirow{3}{*}{$\%$} \\
\hline & & & & & & \\
\hline & & $3^{\text {rd }}$ & $7^{\text {th }}$ & $14^{\text {th }}$ & & \\
\hline \multirow{2}{*}{$\begin{array}{l}\text { Non-infected, non-treated } \\
\text { group (Control negative) }\end{array}$} & Liver & 0 & 0 & 0 & $0 / 9$ & $0 \%$ \\
\hline & Heart & 0 & 0 & 0 & $0 / 9$ & $0 \%$ \\
\hline $\begin{array}{l}\text { Infected, non-treated } \\
\text { group (Control positive) }\end{array}$ & Lung & 3 & 3 & 3 & $9 / 9$ & $100 \%$ \\
\hline \multirow{3}{*}{ Tilmicosin group } & Lung & 3 & 2 & 0 & $5 / 9$ & $55.5 \%$ \\
\hline & Liver & 3 & 2 & 0 & $5 / 9$ & $55.5 \%$ \\
\hline & Heart & 2 & 2 & 0 & $4 / 9$ & $44.4 \%$ \\
\hline \multirow[b]{2}{*}{ Bromhexine group } & Lung & 3 & 3 & 3 & $9 / 9$ & $100 \%$ \\
\hline & Liver & 3 & 3 & 3 & $9 / 9$ & $100 \%$ \\
\hline Thyme oil group & Heart & 3 & 3 & 2 & $8 / 9$ & $88.8 \%$ \\
\hline \multirow{3}{*}{$\begin{array}{l}\text { Tilmicosin + Brohexine } \\
\text { group }\end{array}$} & Lung & 1 & 0 & 0 & $1 / 9$ & $11.1 \%$ \\
\hline & Liver & 2 & 1 & 0 & $3 / 9$ & $33.3 \%$ \\
\hline & Heart & 1 & 0 & 0 & $1 / 9$ & $11.1 \%$ \\
\hline \multirow{3}{*}{$\begin{array}{l}\text { Tilmicosin }+ \text { Thyme oil } \\
\text { group }\end{array}$} & Lung & 1 & 0 & 0 & $1 / 9$ & $11.1 \%$ \\
\hline & Liver & 2 & 0 & 0 & $2 / 9$ & $22.2 \%$ \\
\hline & Heart & 1 & 0 & 0 & $1 / 9$ & $11.1 \%$ \\
\hline
\end{tabular}


Table 3. Effect of treatment with tilmicosin alone or with either thyme oil or bromhexine hydrochloride on blood profile of experimentally infected broiler chickens with Pasteurella multocida.

\begin{tabular}{|c|c|c|c|c|c|c|c|c|}
\hline \multirow[b]{2}{*}{ Treatment groups } & \multicolumn{4}{|c|}{$3^{\text {rd }}$ day of the experiment } & \multicolumn{4}{|c|}{$14^{\text {th }}$ day of the experiment } \\
\hline & $\begin{array}{c}\text { RBCs } \\
\left(10^{6} / \mu \mathrm{I}\right)\end{array}$ & $\begin{array}{c}\mathbf{H b} \\
(\mathbf{g m} / \mathbf{d l})\end{array}$ & $\operatorname{PCV}(\%)$ & $\begin{array}{l}\text { WBCs } \\
\left(10^{3} / \mu \mathrm{I}\right)\end{array}$ & $\begin{array}{c}\text { RBCs } \\
\left(10^{6} / \mu \mathrm{I}\right)\end{array}$ & $\begin{array}{c}\mathbf{H b} \\
(\mathrm{gm} . / \mathrm{dl})\end{array}$ & PCV (\%) & $\begin{array}{c}\text { WBCs } \\
\left(10^{3} / \mu \mathrm{l}\right)\end{array}$ \\
\hline $\begin{array}{l}\text { Non-infected, non-treated group } \\
\text { (Control negative) }\end{array}$ & $4.56 \pm 0.14^{\mathrm{a}}$ & $14.46 \pm 0.07^{\mathrm{a}}$ & $44.02 \pm 1.82^{\mathrm{a}}$ & $13.52 \pm 0.66^{\mathrm{b}}$ & $4.46 \pm 0.07^{\mathrm{a}}$ & $14.48 \pm 0.15^{\mathrm{a}}$ & $49.82 \pm 2.25^{\mathrm{a}}$ & $15.9 \pm 0.69^{b}$ \\
\hline $\begin{array}{l}\text { Infected, non-treated group } \\
\text { (Control positive) }\end{array}$ & $2.82 \pm 0.14^{\mathrm{b}}$ & $7.38 \pm 0.08^{b}$ & $45.1 \pm 1.69$ & $29.06 \pm 2.09^{\mathrm{a}}$ & $2.58 \pm 0.12^{\mathrm{b}}$ & $7.76 \pm 0.14^{\mathrm{b}}$ & $46.82 \pm 1.42^{\mathrm{a}}$ & $35.28 \pm 1.7^{\mathrm{a}}$ \\
\hline Tilmicosin group & $3.31 \pm 0.17^{\mathrm{b}}$ & $8.8 \pm 0.29^{b}$ & $45.26 \pm 1.61^{\mathrm{a}}$ & $23.16 \pm 1^{\mathrm{a}}$ & $4.44 \pm 0.14^{\mathrm{a}}$ & $13.6 \pm 0.45^{\mathrm{a}}$ & $45.36 \pm 0.94^{\mathrm{a}}$ & $15.18 \pm 1.23^{\mathrm{b}}$ \\
\hline Thyme oil group & $3.12 \pm 0.21^{\mathrm{b}}$ & $9.12 \pm 0.25^{\mathrm{b}}$ & $43.92 \pm 0.92^{\mathrm{a}}$ & $27.1 \pm 1.45^{\mathrm{a}}$ & $2.56 \pm 0.12^{\mathrm{b}}$ & $7.6 \pm 0.17^{\mathrm{b}}$ & $44.84 \pm 0.96^{\mathrm{a}}$ & $31.4 \pm 1.82^{\mathrm{a}}$ \\
\hline Tilmicosin+Brohexine group & $4.26 \pm 0.16^{\mathrm{a}}$ & $12.48 \pm 0.81^{\mathrm{a}}$ & $48.22 \pm 0.94^{\mathrm{a}}$ & $14 \pm 2.04^{\mathrm{b}}$ & $4.38 \pm 0.16^{\mathrm{a}}$ & $14.22 \pm 0.23^{\mathrm{a}}$ & $43.58 \pm 1.33^{\mathrm{a}}$ & $16.2 \pm 1.19^{\mathrm{b}}$ \\
\hline Tilmicosin + Thyme oil group & $4.26 \pm 0.09^{\mathrm{a}}$ & $12.86 \pm 0.62^{\mathrm{a}}$ & $45.06 \pm 1.16^{\mathrm{a}}$ & $16.86 \pm 1.29^{\mathrm{b}}$ & $4.44 \pm 0.14^{\mathrm{a}}$ & $14.26 \pm 0.28^{\mathrm{a}}$ & $45.40 \pm 0.85^{\mathrm{a}}$ & $15.92 \pm 1.45^{\mathrm{b}}$ \\
\hline
\end{tabular}

Means with different superscript letters within the same column are significantly different $(\mathrm{p} \leq 0.05)$.

Table 4. Effect of treatment with tilmicosin alone or with either thyme oil or bromhexine hydrochloride on the differential leucocyte count of experimentally infected broiler chickens with Pasteurella multocida.

\begin{tabular}{|c|c|c|c|c|c|c|c|c|}
\hline \multirow[b]{2}{*}{ Treatment groups } & \multicolumn{4}{|c|}{$3^{\text {rd }}$ day of the experiment } & \multicolumn{4}{|c|}{$14^{\text {th }}$ day of the experiment } \\
\hline & $\begin{array}{c}\text { Neutrophils } \\
(\%)\end{array}$ & $\begin{array}{c}\text { Lymphocytes } \\
(\%)\end{array}$ & $\begin{array}{c}\text { Monocytes } \\
(\%)\end{array}$ & $\begin{array}{c}\text { Eosinophils } \\
(\%)\end{array}$ & $\begin{array}{c}\text { Neutrophils } \\
(\%)\end{array}$ & $\begin{array}{c}\text { Lymphocytes } \\
(\%)\end{array}$ & $\begin{array}{c}\text { Monocytes } \\
(\%)\end{array}$ & $\begin{array}{c}\text { Eosinophils } \\
(\%)\end{array}$ \\
\hline $\begin{array}{l}\text { Non-infected non-treated } \\
\text { group (Control negative) }\end{array}$ & $60.0 \pm 0.95^{\mathrm{b}}$ & $33.2 \pm 1.01^{\mathrm{a}}$ & $3.6 \pm 0.40^{\mathrm{a}}$ & $3.2 \pm 0.37^{\mathrm{a}}$ & $58.80 \pm 0.58^{\mathrm{c}}$ & $33.8 \pm .58^{\mathrm{a}}$ & $4.0 \pm 0.32^{\mathrm{a}}$ & $3.4 \pm 0.24^{\mathrm{a}}$ \\
\hline $\begin{array}{l}\text { Infected non-treated group } \\
\text { (Control positive) }\end{array}$ & $66.6 \pm 0.6^{\mathrm{a}}$ & $29.0 \pm 0.63^{\mathrm{a}}$ & $2.4 \pm 0.24^{\mathrm{a}}$ & $2.0 \pm 0.32^{\mathrm{a}}$ & $63.2 . \pm 0.8^{\mathrm{a}}$ & $30.4 \pm 1.12^{\mathrm{a}}$ & $3.6 \pm 0.51^{\mathrm{a}}$ & $2.8 \pm 0.49^{\mathrm{a}}$ \\
\hline Tilmicosin group & $66.2 \pm 1.39^{\mathrm{a}}$ & $28.2 \pm 1.01^{\mathrm{a}}$ & $3.0 \pm 0.32^{\mathrm{a}}$ & $2.6 \pm 0.51^{\mathrm{a}}$ & $61.8 \pm 0.97^{\mathrm{ab}}$ & $31.4 \pm 0.74^{\mathrm{a}}$ & $3.0 \pm 0.0^{\mathrm{a}}$ & $3.0 \pm 0.32^{\mathrm{a}}$ \\
\hline Bromhexine group & $66.0 \pm 0.63^{\mathrm{a}}$ & $28.4 \pm 0.24^{\mathrm{a}}$ & $3.0 \pm 0.44^{\mathrm{a}}$ & $2.6 \pm 0.24^{\mathrm{a}}$ & $63.2 \pm 0.37^{\mathrm{a}}$ & $30.2 \pm 0.2^{\mathrm{a}}$ & $3.4 \pm 0.24^{\mathrm{a}}$ & $3.2 \pm 0.2^{\mathrm{a}}$ \\
\hline Thyme oil group & $66.4 \pm 1.25^{\mathrm{a}}$ & $28.8 \pm 1.36^{\mathrm{a}}$ & $2.6 \pm 0.24^{\mathrm{a}}$ & $2.2 \pm 0.20^{\mathrm{a}}$ & $62.6 \pm 0.68^{\mathrm{a}}$ & $30.4 \pm 0.68^{\mathrm{a}}$ & $3.6 \pm 0.24^{\mathrm{a}}$ & $3.6 \pm 0.24^{\mathrm{a}}$ \\
\hline $\begin{array}{l}\text { Tilmicosin+Brohexine } \\
\text { group }\end{array}$ & $62.2 \pm 2.03^{\mathrm{ab}}$ & $31.8 \pm 1.74^{\mathrm{a}}$ & $3.4 \pm 0.51^{\mathrm{a}}$ & $2.6 \pm 0.4^{\mathrm{a}}$ & $59.2 \pm .49^{\mathrm{bc}}$ & $32.8 \pm 1.24^{\mathrm{a}}$ & $4.2 \pm 0.58^{\mathrm{a}}$ & $3.8 \pm 0.37^{\mathrm{a}}$ \\
\hline Tilmicosin + Thyme oil & $61.20 \pm 0.97^{\mathrm{ab}}$ & $32.2 \pm 1.2^{\mathrm{a}}$ & $3.8 \pm 0.49^{\mathrm{a}}$ & $2.8 \pm 0.37^{\mathrm{a}}$ & $59.0 \pm 0.55^{\mathrm{bc}}$ & $32.6 \pm .93^{\mathrm{a}}$ & $3.6 \pm 0.24^{\mathrm{a}}$ & $3.60 \pm 0.51^{\mathrm{a}}$ \\
\hline
\end{tabular}

Means with different superscript letters within the same column are significantly different $(\mathrm{p} \leq 0.05)$.

Table 5. Effect of treatment with tilmicosin alone or with either thyme oil or bromhexine hydrochloride on liver and kidney functions of experimentally infected broiler chickens with Pasteurella multocida.

\begin{tabular}{|c|c|c|c|c|c|c|c|c|}
\hline \multirow[b]{2}{*}{ Treatment groups } & \multicolumn{4}{|c|}{$3^{\text {rd }}$ day of the experiment } & \multicolumn{4}{|c|}{$14^{\text {th }}$ day of the experiment } \\
\hline & $\begin{array}{l}\text { ALT } \\
(\mathbf{U} / \mathbf{L})\end{array}$ & $\begin{array}{c}\text { AST } \\
(\mathbf{U} / \mathbf{L})\end{array}$ & $\begin{array}{l}\text { Uric acid } \\
(\mathbf{m g} / \mathbf{d l})\end{array}$ & $\begin{array}{l}\text { Creatinine } \\
(\mathbf{m g} / \mathbf{d l})\end{array}$ & $\begin{array}{l}\mathbf{A L T} \\
(\mathbf{U} / \mathbf{L})\end{array}$ & $\begin{array}{l}\text { AST } \\
(\mathbf{U} / \mathbf{L})\end{array}$ & $\begin{array}{l}\text { Uric acid } \\
(\mathbf{m g} / \mathbf{d l})\end{array}$ & $\begin{array}{c}\text { Creatinine } \\
(\mathrm{mg} / \mathrm{dl})\end{array}$ \\
\hline $\begin{array}{l}\text { Non-infected non-treated } \\
\text { group (Control negative) }\end{array}$ & $11.60 \pm 0.93^{\mathrm{b}}$ & $180.2 \pm 11.57^{\mathrm{b}}$ & $9.00 \pm 0.71^{\mathrm{c}}$ & $0.35 \pm 0.03^{\mathrm{b}}$ & $12.40 \pm 0.75^{\mathrm{b}}$ & $149.0 \pm 8.14^{\mathrm{b}}$ & $8.20 \pm 0.73^{b}$ & $0.36 \pm 0.04^{b}$ \\
\hline $\begin{array}{l}\text { Infected non-treated group } \\
\text { (Control positive) }\end{array}$ & $27.00 \pm 2.07^{\mathrm{a}}$ & $252.8 \pm 12.53^{\mathrm{a}}$ & $17.40 \pm 0.81^{\mathrm{a}}$ & $0.78 \pm 0.08^{\mathrm{a}}$ & $31.80 \pm 1.16^{\mathrm{a}}$ & $287.8 \pm 14.63^{\mathrm{a}}$ & $17.00 \pm 0.71^{\mathrm{a}}$ & $0.79 \pm 0.04^{\mathrm{a}}$ \\
\hline Tilmicosin group & $25.00 \pm 1.52^{\mathrm{a}}$ & $261.00 \pm 17.95^{\mathrm{a}}$ & $14.40 \pm 1.5^{\mathrm{ab}}$ & $0.58 \pm 0.03^{\mathrm{a}}$ & $18.60 \pm 3.37^{\mathrm{b}}$ & $179.6 \pm 8.29^{\mathrm{b}}$ & $12.40 \pm 0.81^{\mathrm{ab}}$ & $0.56 \pm 0.05^{\mathrm{b}}$ \\
\hline Bromhexine group & $23.80 \pm 1.77^{\mathrm{a}}$ & $286.00 \pm 16.84^{\mathrm{a}}$ & $15.60 \pm 1.03^{\mathrm{a}}$ & $0.69 \pm 0.05^{\mathrm{a}}$ & $31.00 \pm 1.76^{\mathrm{a}}$ & $297.2 \pm 3.72^{\mathrm{a}}$ & $16.80 \pm 1.5^{\mathrm{a}}$ & $0.68 \pm 0.03^{\mathrm{a}}$ \\
\hline Thyme oil group & $24.40 \pm 1.57^{\mathrm{a}}$ & $292.80 \pm 14.1^{\mathrm{a}}$ & $15.00 \pm 1.26^{\mathrm{ab}}$ & $0.64 \pm 0.06^{\mathrm{a}}$ & $30.40 \pm 0.68^{\mathrm{a}}$ & $289.4 \pm 7.08^{\mathrm{a}}$ & $15.40 \pm 0.68^{\mathrm{a}}$ & $0.73 \pm 0.04^{\mathrm{a}}$ \\
\hline Tilmicosin+Brohexine group & $14.80 \pm 0.86^{\mathrm{b}}$ & $192.8 \pm 6.57^{\mathrm{b}}$ & $10.80 \pm 0.8^{\mathrm{bc}}$ & $0.47 \pm 0.06^{\mathrm{b}}$ & $13.80 \pm 0.66^{\mathrm{b}}$ & $170.0 \pm 6.19^{\mathrm{b}}$ & $8.00 \pm 1.14^{\mathrm{b}}$ & $0.40 \pm 0.03^{\mathrm{b}}$ \\
\hline Tilmicosin + Thyme oil group & $14.60 \pm 0.5^{\mathrm{b}}$ & $189.2 \pm 6.01^{\mathrm{b}}$ & $9.40 \pm 0.75^{\mathrm{c}}$ & $0.36 \pm 0.02^{\mathrm{b}}$ & $14.40 \pm 0.1^{\mathrm{b}}$ & $153.4 \pm 5.53^{\mathrm{b}}$ & $7.80 \pm 1.59^{\mathrm{b}}$ & $0.31 \pm 0.02^{\mathrm{b}}$ \\
\hline
\end{tabular}

Means with different superscript letters within the same column are significantly different $(\mathrm{p} \leq 0.05)$. AST: Aspartate Aminotransferase, ALT: Alanine Aminotransferase 


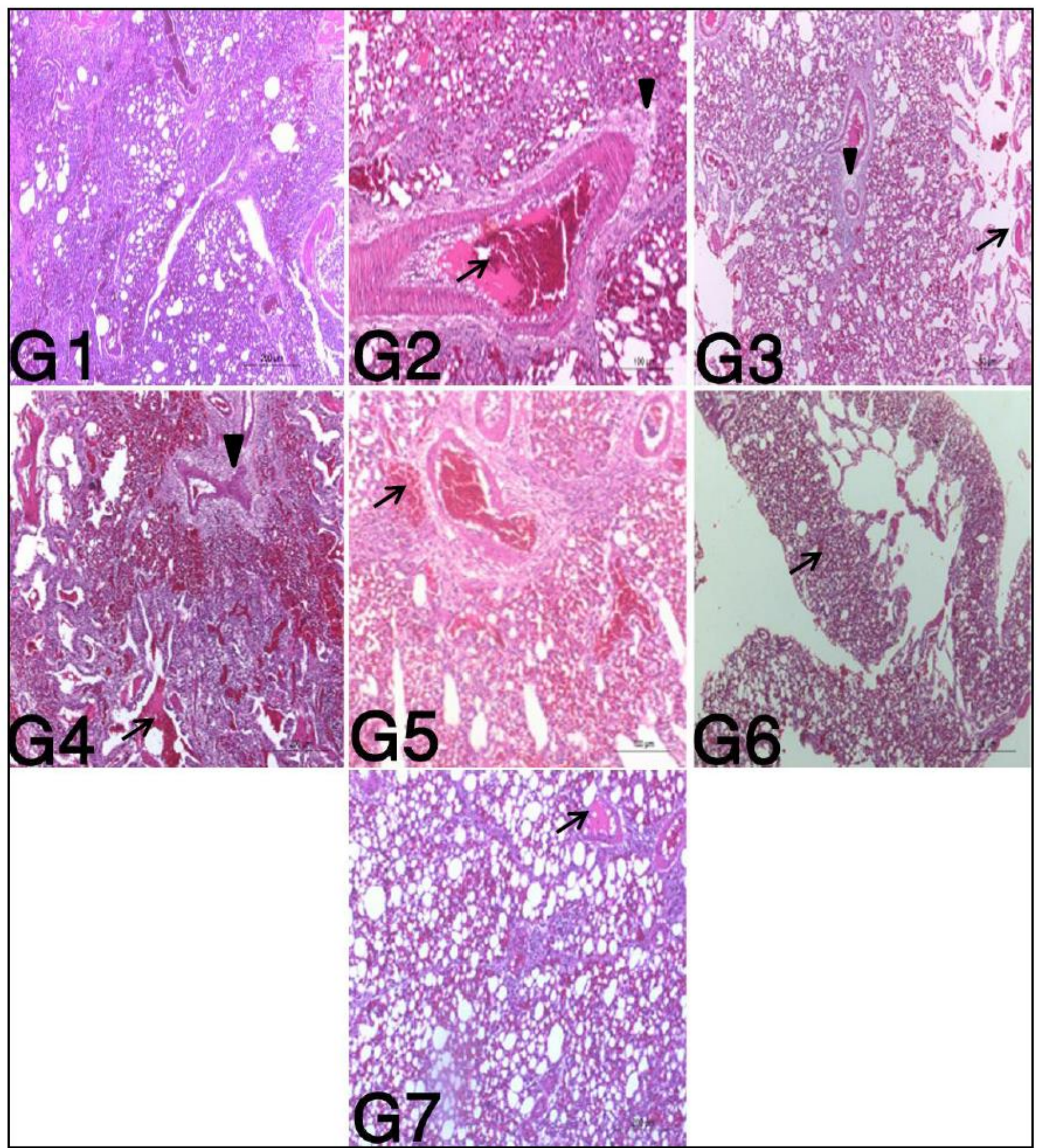

Figure 1. Lung sections on the $3^{\text {rd }}$ day of treatment in different broiler chicken groups infected with Pasteurella multocida. Normal lung with normal bronchi and bronchioles in control negative group (G1); Congestion, hemorrhage, perivascular edema, and lymphocytic infiltration in the interalveolar cell in control positive group (G2); Vascular thrombosis, perivascular edema, few leucocyte infiltrations together with mild atelectasis and emphysema. In tilmicosin treated group (G3); Severe congestion in the vasculature, perivascular edema also obliteration of most alveoli by RBCs and inflammatory cell in bromhexine treated group (G4); Severe hemorrhage in the tubular septum in Thyme oil treated group (G5); Normal bronchi and alveoli except slight congestion in the interalveolar capillaries in tilmicosin +bromhexine treated group (G6) and Nearly normal lung with slight congestion of the vasculature in tilmicosin +thyme oil treated group (G7). 


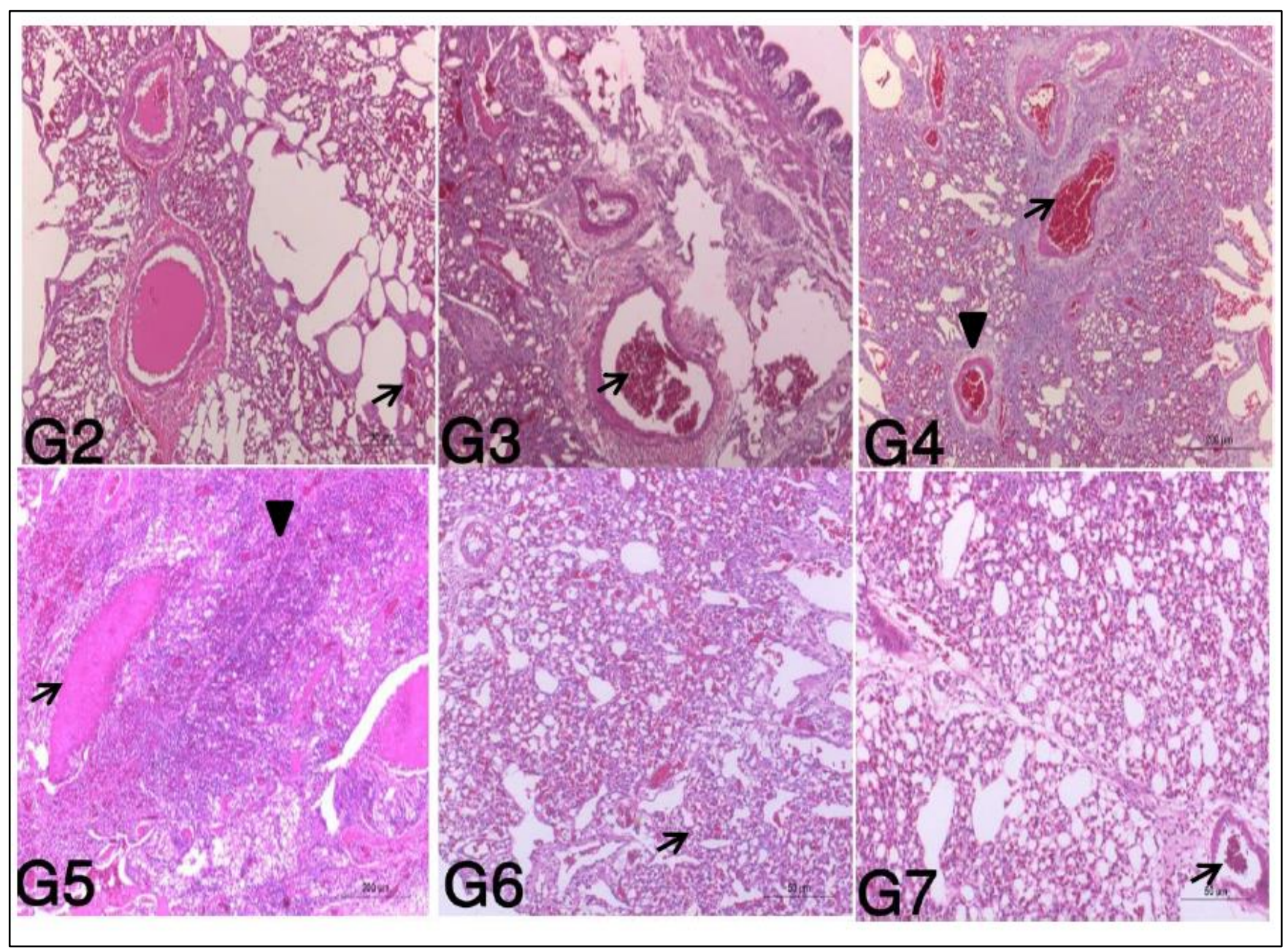

Figure 2. Lung sections on the $14^{\text {th }}$ day of treatment in different broiler chicken groups infected with Pasteurella multocida. Normal lung with normal bronchi and bronchioles in control negative group (G1); Thrombosis with vacuolation of tunica media together with slight atelectasis and emphysema in control positive group (G2); Bronchial epithelium with slight congestion of the blood vessels of lamina propria, especially veins and lymphocytic vessels in tilmicosin treated group (G3); Severe congestion of the intertubular blood vessels with moderate perivascular edema in bromhexine treated group (g4); Severe congestion of the vasculature together with focal necrosis surround by giant cells and lymphocytes in thyme oil-treated group (G5); Normal lung except slight emphysema and atelectasis in tilmicosin +bromhexine treated group (G6) and Normal lung except slight congestion of the vasculature in tilmicosin +thyme oil treated group (G7). 


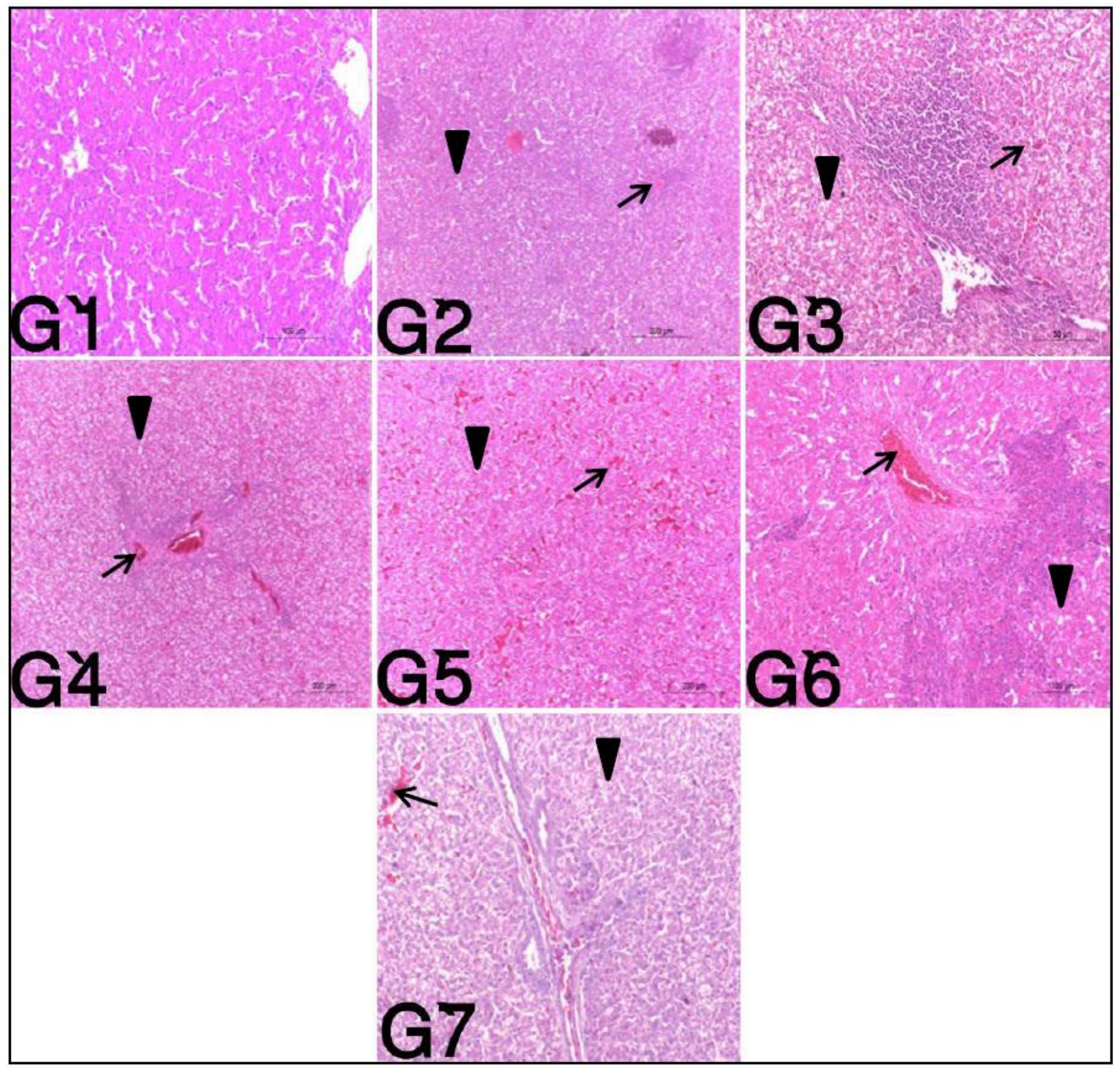

Figure 3: Hepatic sections on $3^{\text {rd }}$ day of treatment in different broiler chicken groups infected with Pasteurella multocida. Normal hepatic architecture with normal hepatocytes, centrally located vesicular nucleus, also normal central and veins in control negative group (G1); Congestion, hemorrhage, focal lymphocytic infiltration, and vacuolar degeneration within hepatocytes in control positive group (G2); Mild congestion, moderate leucocyte infiltrations, and severe vacuolar degeneration in tilmicosin treated group (G3); Congestion, mild leucocytic aggregation in the portal area, and severe vacuolar degeneration in bromhexine treated group (G4); Moderate congestion, disorganization of hepatic cord with focal leucocytic aggregation in portal triads in thyme oil-treated group (G5); Moderate congestion, moderate inflammatory cell infiltrations also mild vacuolar degenerations in tilmicosin +bromhexine treated group (G6) and mild congestion, very mild leucocytic aggregations in the portal area, and severe vacuolar degeneration in tilmicosin +thyme oil treated group (G7). 

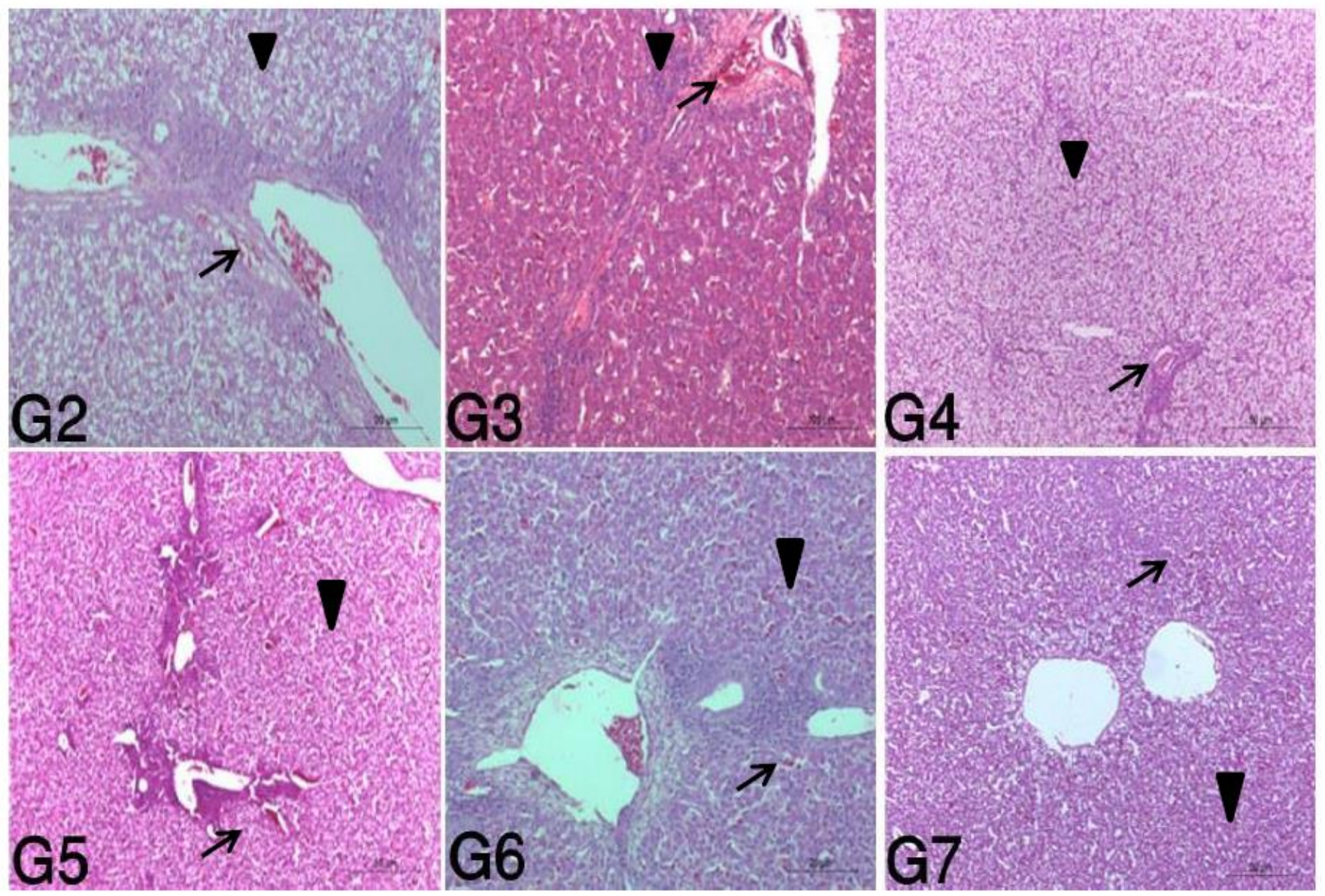

Figure 4. Hepatic sections on the $14^{\text {th }}$ day of treatment in different broiler chicken groups infected with Pasteurella multocida. Normal hepatic architecture with normal hepatocytes, centrally located vesicular nucleus, normal central and veins in control negative group (G1); Severe vacuolar degeneration within hepatocytes, congestion of hepatic blood vessels, and few mononuclear cell infiltrations in the portal area in control positive group (G2); Slight congestion with mild leucocyte infiltrations in the portal area in tilmicosin treated group (G3); Vacuolar degeneration, thrombosis in the hepatic artery, and dissociation of hepatocytes in bromhexine treated group (G4); Severe vacuolar degeneration and moderate congestion of the vasculature also mononuclear cell infiltrations in the portal area in thyme oil-treated group (G5); Mild congestion, very mild vacuolar degeneration, and few mononuclear cell aggregations in the portal area in tilmicosin +bromhexine treated group (G6) and slight congestion of the vasculature with mild vacuolar degeneration in tilmicosin +thyme oil treated group (G7). 


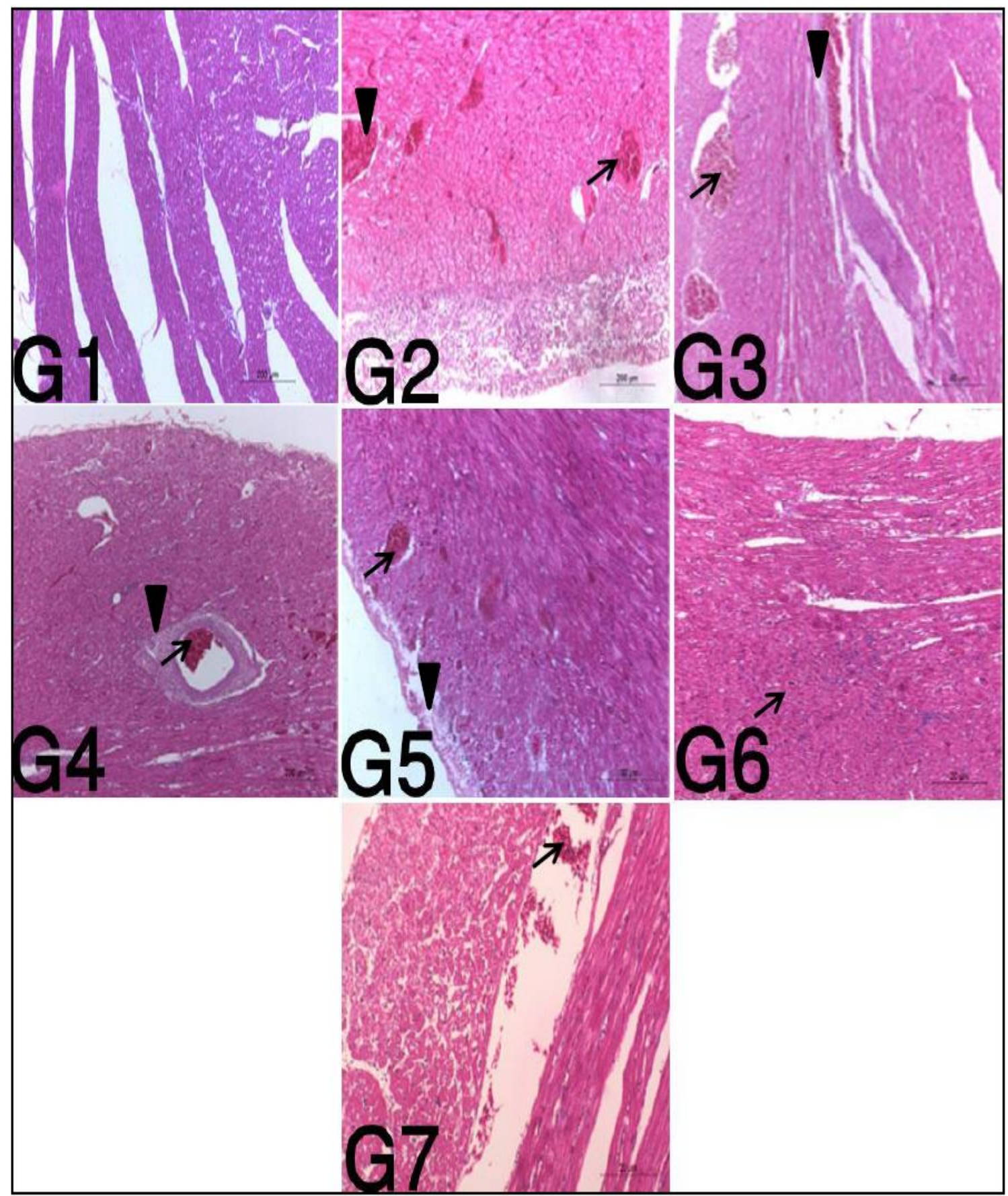

Figure 5. Heart sections of on $3^{\text {rd }}$ day of treatment in different broiler chicken groups infected with Pasteurella multocida. Normal heart in control negative group (G1); Congestion in coronaries, hemorrhage between cardiac muscles, edema in the epicardial region, and epicarditis in control positive group (G2); Moderate congestion of coronaries and perivascular edema in tilmicosin treated group (G3); Moderate congestion in the coronaries, perivascular edema, and lymphocytic infiltrations in bromhexine treated group (G4); Severe congestion of coronaries, moderate epicardiac edema and mild phagocytic activation thyme oil treated group (G5); Focal lymphocytic infiltrations in the myocardium in tilmicosin +bromhexine treated group (G6); Slight congestion of coronaries with focal necrosis of some muscle bundles in tilmicosin +thyme oil treated group (G7). 


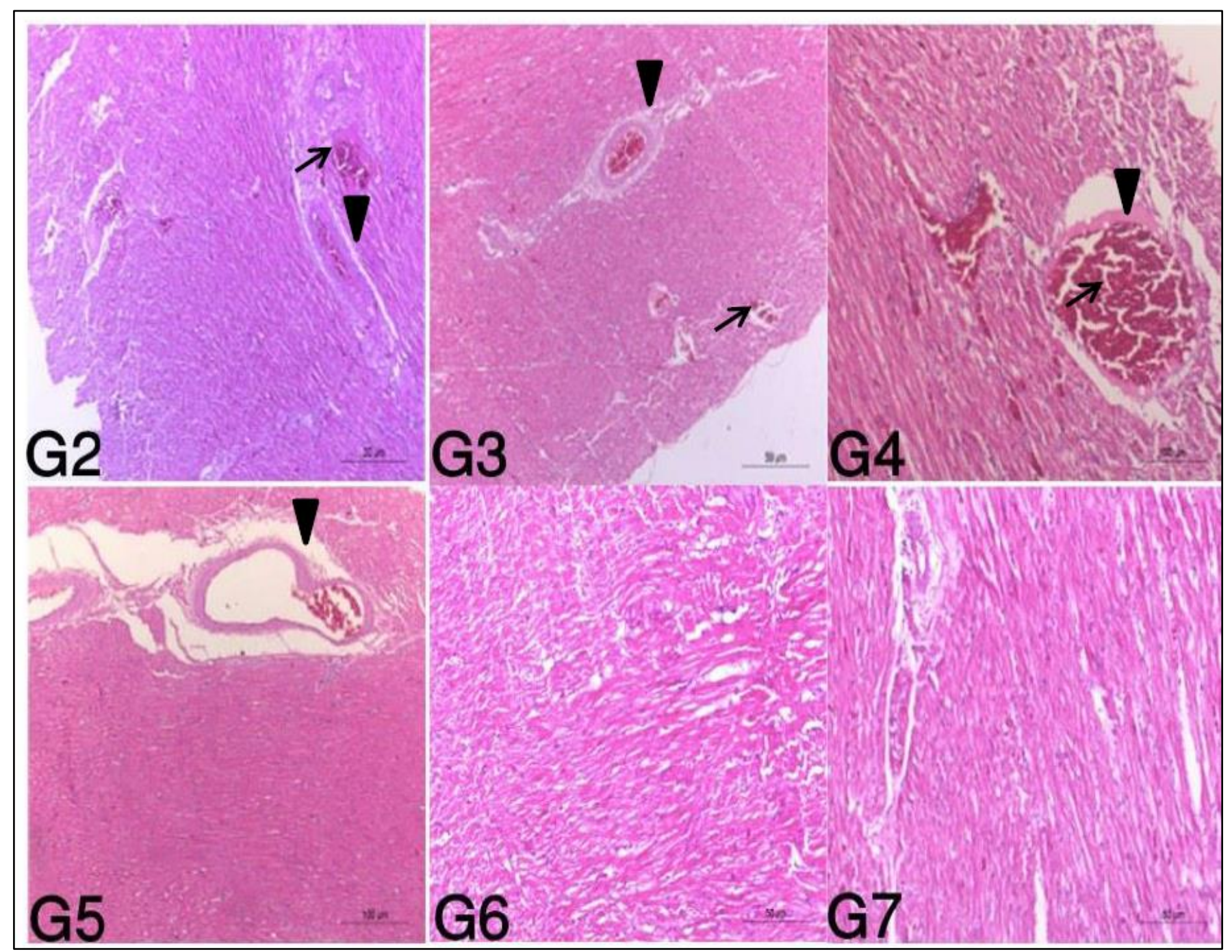

Figure 6. Heart sections on $14^{\text {th }}$ day of treatment in different broiler chicken groups infected with Pasteurella multocida. Normal heart in control negative group (G1); moderate congestion in coronaries, Zenger necrosis of some muscle bundles together with perivascular edema in control positive group (G2); mild congestion of coronaries and mild perivascular edema in tilmicosin treated group (G3); Severe congestion of coronaries and slight perivascular edema in bromhexine treated group (G4); Severe perivascular edema in thyme oil-treated group (G5); normal cardiac muscle with normal vasculature in tilmicosin +bromhexine treated group (G6) and normal cardiac muscle in tilmicosin +thyme oil treated group (G7).

\section{DISCUSSION}

Experimental infection with $P$. multocida induced severe clinical signs included off food, nasal discharge, cough, ruffled feather, watery green diarrhea, or even sudden mortality in non-medicated birds and these findings are in agreement with results of Mohamed (2009). A high mortality rate $(44.4 \%)$ was recorded in the non-medicated group. A similar observation had been recorded in chickens infected with P. multocida (Mohamed 2009; Sonone et al., 2011). It was clear that experimental infection with $P$. multocida induced a low mortality rate
$(11.1 \%)$ in the tilmicosin treated group. The findings proved that concurrent administration of tilmicosin with bromhexine or thyme oil for three consecutive days is highly effective in the treatment of pasteurellosis as indicated by no mortality during the experiment compared to groups treated with a single agent. Invasion of lung, liver, and spleen via $P$. multocida decreased by treatment of tilmicosin alone or concurrent with bromhexine or thyme oil may be due to the antibacterial action of these drugs. The antibacterial activity of tilmicosin might be attributed to its accumulation within avian phagocytic cells. Also, phagocytosis of $P$. multocida and 
lipopolysaccharide exposure increases tilmicosin uptake by the avian phagocytes and the presence of opsonized $P$. multocida enhances the release of tilmicosin from the phagocytes. Also, intracellular tilmicosin increases cellular lysosomal production in all three chicken phagocyte types (Scorneaux and Shryock, 1998). According to McKellar et al. (2004), the release of drug from intracellular sites during phagocytosis can help to maintain sustained tissue concentrations and subject bacteria to prolonged exposure appropriate for a time-dependent drug. Moreover, tilmicosin has an active post-antibiotic effect and postantibiotic sub-MIC effect on P. multocida, which may impede disease progression by enhancing the animal's immune response to eliminate a weakened bacterial population (Lim and Yun, 2001). Thyme oil exhibit a significant antibacterial effect against many Gramnegative and Gram-positive microorganisms (Amat et al., 2019).

The results of hematology in the present study showed anemia indicated by significant decrease in RBCs count and $\mathrm{Hb}$ concentration in groups $\left(2,4\right.$ and 5) at $3^{\text {rd }}$ day of infection and group (2) at the end of experiment which could be attributed to the hemolytic effect of the $P$. multocida endotoxin as stated by Diallo and Frost (2000). The leukogram in groups (2, 4 and 5) showed leukocytosis, due to neutrophilia which might be attributed to the endotoxin of P. multocida (Sonone et al., 2011) as well as elevated heterophils and WBCs in diseased birds may be recorded as the primary defense mechanism against any pathogen to prevent the spread of infection (Ahamefule et al., 2006). Treatment of infected chicken with bromhexine or thyme oil alone showed nonsignificant changes in the blood picture. On the other hand, concurrent medication with Tilmicosin and thyme oil or bromhexine revealed improvement of blood picture as shown by the significant increase in the RBCs and $\mathrm{Hb}$ concentration in the $\mathrm{G}_{6}, \mathrm{G}_{7}$ as compared with $\mathrm{G}_{2}$ at $3^{\text {rd }}$ day and $14^{\text {th }}$ post medication, that might be due to the enhancement of antibacterial activity of tilmicosin by bromhexine in addition to the antioxidant activity of thyme oil (Aljabeili et al., 2018; Saricaoglu and Turhan 2018).

The values of ALT, AST, uric acid, and creatinine in the serum of chicken in $\mathrm{G}_{2}$ were significantly $(P \leq 0.05)$ increased in comparison to the control group at $3^{\text {rd }}$ and $14^{\text {th }}$ days post-infection. The increased value in ALT and AST could be due to hepatopathy as well as degenerative changes caused by $P$. multocida or its endotoxins (Campbell and Coles, 1986). Similar results obtained by (Sonone et al., 2011) in broiler chickens. The increased values of uric acid and creatinine could be due to the negative effect of the $P$. multocida or its endotoxin on the kidney functions (Mohamed, 2009). The current study revealed that the birds given combination of tilmicosin with thyme oil or bromhexine showed amelioration of serum enzymes in $\mathrm{G}_{6}$ and $\mathrm{G}_{7}$ at $3^{\text {rd }}$ and $14^{\text {th }}$ days of the experiment and $14^{\text {th }}$ days of the experiment in case of tilmicosin only whereas no changes in cases of thyme oil or bromhexine groups, this could be due to the enhancement activities of tilmicosin by bromhexine or thyme oil.

In the present study, macroscopic lesions in diseased chickens including congested body, enlarged liver with pinpoint grayish-white foci, fibrinous pericarditis, and enlarged congested spleen had come in accordance with (Srinivasan et al., 2011). The microscopic examination of different tissues from infected chickens showed vacuolar degeneration, hemorrhages, and congestion in livers similar to that recorded by Shivachandra et al. (2005), lymphocytic depletion of the spleen, fibrinous pericarditis in the cardiac tissue and severe congestion beside leucocytic infiltration, the lung showed congestion, hemorrhages and leucocytic infiltrations which might be attributed to the effect of $P$. multocida endotoxins (Christensen and Bisgaard, 2000). These results were exceedingly compatible with those reported by Afifi and El-Nesr (2013) and Panna et al., (2015). Tilmicosintreated birds exhibited less severe histopathological lesions, probably related to the antibacterial and antiinflammatory activities of Tilmicosin. Similarly, infected chicken treated with Tilmicosin in combination with bromhexine or thyme oil showed marked reductions in the severity of histopathological lesions probably due to the potent antibacterial activity and antioxidant activities of thyme oil (Aljabeili et al., 2018).

\section{CONCLUSION}

This study showed that the clinically observed damage in chickens infected with $P$. multocida could be ameliorated by the combination of tilmicosin with bromhexine or thyme oil. This protective effect could reduce the use of antibiotics in livestock, human exposure to antibiotic residues and bacterial resistance to antibiotics. Furthermore, tilmicosin can be used for the effective treatment of pasteurellosis in chicken. The combination of tilmicosin and bromhexine or thyme oil was more potent against Pasteurella multocida infection than each treatment alone. 


\section{DECLARATIONS}

\section{Competing interests}

The authors have no competing interest to declare.

\section{Author s' contribution}

Dr. Abeer, Dr. Nema, Prof. Dr. Hossny, and Prof. Dr. Abd El Nasser involved in the collection of data, developed the idea of research and design, analysis and interpretation of data; also involved in drafting and revising the manuscript. Prof. Dr. Elham revised the article. Dr. Fatma designed the figures.

\section{REFERENCES}

Afifi SI and El-Nesr KA (2013). Bacteriological, pathological and immunohistochemical studies on Pasteurella spp. isolated from ducks in Beni-Suef Governorate. Egypt. Egyptian Journal of Comparative Pathology and Clinical Pathology, 26(1): 28- 48.

Ahamefule F, Edouk G, Usman A, Amaefule K and Oguike S. (2006). Blood chemistry and hematology of weaner rabbits fed sun-dried, ensiled and fermented cassava peel based diets. Pakistan Journal of Nutrition, 5(3): 248 -253.

Aljabeili HS, Barakat H and Abdel-Rahman HA (2018). Chemical Composition, Antibacterial and Antioxidant Activities of Thyme Essential Oil (Thymus vulgaris). Food and Nutrition Sciences. 9: 433-446.

Amany A and Abd-Alla M (1997). Clinicopathological studies on the effect of Pasteurella multocida in chicken and ducks. Egyptian Journal of Comparative Pathology and Clinical Pathology, 10(2): 149-159.

Amat S, Baines D, Timsit E, Hallewell $\mathbf{J}$ and Alexander TW (2019). Essential oils inhibit the bovine respiratory pathogens Mannheimia haemolytica, Pasteurella multocida and Histophilus somni and have limited effects on commensal bacteria and turbinate cells in vitro. Journal of Applied Microbiology, 126(6):1668-1682.

Amer MM, Hanafei AEl-H A, EL-bayomi KM and Zohair GA (2009). Comparative study on the efficacy of antimycoplasma drugs on Performance of commercial broiler flocks from infected breeders, Global Veterinaria, 3 (2): 69-74.

Bakkali F, Averbeck S, Averbeck D and Idaomar M (2008). Biological effects of essential oils - A review. Food and Chemical Toxicology, 46(2): 446-475.

Campbell TW and Coles EH (1986). Avian Clinical Pathology, in Veterinary Clinical Pathology, $4^{\text {th }}$ Edition, W.B. Saunders Company. Philadelphia, London and Toronto.

Christensen JP and Bisgaard M (2000). Fowl cholera. Revue Scientifique ET Technique, 19: 626-637.

Diallo IS and Frost AJ (2000). Characteristics of a haemolytic extract from avian Pasteurella multocida. Veterinary Microbiology, 72(1-2): 37-45.

Santurio DF, Jesus FPK, Zanette RA, Schlemmer KB, Fraton A and Martins Fries LL (2014). Antimicrobial activity of the essential oil of thyme and thymol against Escherichia coli strains. Acta Science Veterinary, 42(1):1-4.
Doolan PD, Alen EL and Theil GB (1962). A clinical appraisal of the plasma concentration and endogenous clearance of creatinine, The American Journal of Medicine, 32(1): 65-79.

El-Mahmoudy A M, Gheith IM, Elmajdoub AA and Awidat SK (2018). In-vivo assessment of the antipyretic activity of tilmicosin, African Journal of Pharmacy and Pharmacology, 12(14): 176-182.

Feizi A, Bijanzad P and Kaboli K (2013). Effects of thyme volatile oils on performance of broiler chickens. European Journal of Experimental Biology, 3 (1): 250-254.

Feldman BF, Zinkl JG and Jain NC (2000). Schalm's Veterinary Hematology. $5^{\text {th }}$ Edition, Lippincott Williams \& Wilkins, $1120-1124$.

Glisson JR, Hofacre CL and Christensen JP (2013). In: Diseases of Poultry; Thirteenth Edition, Swayne D.E., Editor in Chief, Glisson J.R., McDougald L.R., Nolan L.K., Suarez D.L. \& Nair V., Associate Editors. Wiley-Blackwell, Ames, Iowa, USA and Oxford, UK, pp. 807-823.

Gubbi S and Jarag R (2009). Liquisolid technique for enhancement of dissolution properties of bromhexine hydrochloride. Research Journal of Pharmacy and Technology, 2(2): 382-386.

Jain NC (1986). Hematologic techniques, In: Schalm's veterinary haematology (Jain, N. C. Ed) Lea and Febigen. Philadelphia, p. 23.

Kageyama NA (1971). A direct colorimetric determination of uric acid in serum and urine with uricase-catalase system. Clinica Chimica Acta, 31(2): 421-426.

Lim J and Yun H (2001). Postantibiotic effects and postantibiotic sub-MIC effects of erythromycin, roxithromycin, tilmicosin, and tylosin on Pasteurella multocida. International Journal of Antimicrobial Agents, 17(6): 471-476.

McKellar QA, Sanchez Bruni SF and Jones DG (2004). Pharmacokinetic/pharmacodynamic relationships of antimicrobials drugs used in veterinary medicine. Journal of Veterinary Pharmacology and Therapeutics, 27(6): 503-514.

Mestorino ON and Errecalde JO (2004). Tilmicosin: A new macrolide antibiotic for veterinary use. Analecta Veterinary Medicine, 24(2):21-28.

Mohamed SM (2009). Hematological biochemical immunological and pathological studies on pasteurellosis in chicken. Egyptian Journal of Comparative Pathology and Clinical Pathology,22(2):125-209.

Panna SN, Nazir NH, Rahman MB, Ahamed S Saroare MG Chakma S Kamal T and Majumder UH (2015). Isolation and molecular detection of Pasteurella multocida Type A from naturally infected chickens, and their histopathological evaluation in artificially infected chickens in Bangladesh. Journal of Advanced Veterinary and Animal Research, 2(3): 338-345.

Pathak K and Das RJ (2013). Herbal medicine- a rational approach in health care system. International Journal of Herbal Medicine, 1(3): 86-89.

Reitman and Frankel S (1957). A colorimetric method for determination of AST and ALT. American Journal of Clinical Pathology, 28(1): 56-63.

Saricaoglu FT and Turhan S (2018). Antimicrobial activity and antioxidant capacity of thyme, rosemary and clove essential oils and their mixtures. Journal of Innovative Science and Engineering, 2(1): 25-33. 
Scorneaux B and Shryock TR (1998). Intracellular accumulation, subcellular distribution, and efflux of tilmicosin in chicken phagocytes. Poultry Science, 77(10): 1510-1521.

Seiple IB, Zhang Z, Jakubec P, Langlois-Mercier A, Wright PM, Hog DT, Yabu K, Allu SR, Fukuzaki T and Carlsen PN (2016). A platform for the discovery of new macrolide antibiotics. Nature, 533:338-345.

Shivachandra SB, Kumar AA, Gautam R Saxena MK Chaudhuri $\mathrm{P}$ and Srivastava SK (2005). Detection of multiple strains of Pasteurella multocida in fowl cholera outbreaks by polymerase chain reaction-based typing. Avian Pathology, 34(6): 456-462.

Siddappa K and Hanamshetty PC (2016). Spectrophotometric quantitative determination of bromhexine hydrochloride in bulk and pharmaceutical dosage form using $\mathrm{p}$ - nitrobenzaldehyde reagent. International Journal of Pharmaceutical Sciences Review and Research, 39 (2): 260265.

Snedecor GW and Cochran WG (1982). Statistical Methods. $6^{\text {th }}$ Edition. Iowa State University Press, Ames, USA, p. 593.

Sonone S, Swamy M and Verma Y (2011). Ameliorative Effect of Mannan oligosaccharide on pathology of fowl cholera in broiler birds. Asian Journal of Poultry Science, 5(2): 86-98.

Srinivasan P, Gopalakrishnamurthy TR, Mohan B and Saravanan $S$ (2011). Occurrence of sub-acute fowl cholera in a broiler flock. Tamilnadu Journal of Veterinary and Animal Sciences, 7 (1): 45-47.

Varley H (1980). Practical Clinical Biochemistry, $5^{\text {th }}$ Ed, William Heinemann Medical Books, LTD, London. 